CASE OP A CHILD WHO HAD SWALLOWED A PIECE OF GLASS.

By Mr. Chilcote, Surgeon.

A rine child, about four years of age, residing in Monmonth Court, Whitconb Street, Haymarket, was attacked, during the past week, with small-pox. On Monday last, it having hecome necessary to give an aperient, a wine-glass, containing a portion of a purgative mixture, was placed to his mouth. The little patient being at the time in a state of delirium, a piece was bitten out with great violence, and swallowed. The distress of the parents at the occurrence of this unfortunate accident, may be easily imagined. On Thursday evening, (the patient having been also seen by Mr. Jewell, ) after the exhibition of an aperient, and to the great surprise and satisfaction of all, a dark-coloured and copious evacuation from the bowels took place, and the piece of glass was found in the freces. It measures exactly one inch in length, terminating in a point almost as sharp as that of a penknife, and about half an inch in width, one of its sides also having a point exceedingly acute. During its passage through the alimentary canal, there was no uneasiness or pain, except what was necessarily produced by the operation of the medicine. The child is doing well.

4, Great Pulteney St., Golden Square, September 28th, 1829.

\section{BRITISH COLLEGE OF SURGEONS.}

\section{To the Editor of The Lancet.}

$S_{1} n,-I$ have been a practitioner in medicine and surgery upwards of twenty years, but I have never chosen to obtain the sanetion of any of the corporate bodies for that purpose. I have adopted this line of conduct upon the fullest conviction, that there is not a corporate body in the United Kingdom to which it is not discreditable to belong; they, one and all, have for their sole object the acquisition of wealth, and that by means the most unfair and disbonourable. In confirmation of this opinion, I have only to refer to the pages of Trne Lancre, in which you have so ably exposed the seltishness and infamous chicanery of these monopolists. In those pages will also be found a proposition for putting down all these nuisances, by the formation of a national college of physic and surgery in their steal; but as the plan did not appear, at the time, to fall in with your views, I forbore to press it further upon you.

I have leant, with the lighest satisfaction, that it is in contemplation to form a new college of surgeons upon liberal and enlightened principles, but I deeply regret that its views are not more extensire. Notbing can be better devised than the manner in which it is purposed to examine candidates for diplomas; but why confine these examinations to diplomas for surgery only? Is not this still to keep up that ioju. rious and injudicious distinction between medicine and surgery, which does not exist in nature, and which, probably, would never have existed at all, but for the pride and indolence of our university M.D.s.

Nature, and the very constitution and wants of society, require that the great body of practitioners should practise both medi. cine aud surgery. That a national hospital for the acquisition of both, and a national college to examine all candidates for ad. mission into the profession, are imperatively demanded, is self-evident; for if the preser. vation of life and health be a matter of national importance, it is but just and expe. dierst that the nation should provide a suitable establishment for the education of those to whom the preservation of life and health is entrusted. I shall not here dilate upon the advantages which such an institution would possess over our eleemosynary foundations, which were never designed by their projectors for schools of medicine and surgery, and for which they are altogether inadequate, but shall proceed to submit to the consideration of the members of the British College of Surgeons themselves, and to the profession at large, the following propositions :-

1st. That the British College of Surgeons exchange its title for that of the National College of Physic and Surgery; and that the examiners take upon themselves the extend. ed powers in the examination of candidates for diplomas, which such a change of tille implies.

2d. That the members of the British College of Surgeons, and the members of the profession at large, unite in a petition to parliament for the erection (in London) of a national hospital, capable of containing, at least, 2000 patients.

3d. That to such hospital, professors, physicians, surgeons, \&c., be attacbed, (with aclequate salaries,) whose time and services shall be exclusively devoted to the instruction of the students, and the cure of the pa. tients within the hospital.

; th. That students be admitted to the different lectures, and to the practice of the hospital, upon the payment of a moderate premium, or gratuitously, as may be deemed most expredient.

5th. That persons shall still be at liberty to study their profession, when, where, and in whatever manner they may think proper; but that, from and after any certain date, no one shall be permitted to practise medicine or surgery, witlout first obtainigg a diplona 